\title{
To Evaluate Shear Bond Strength of Resin Composite to Theracal Lc, Biodentine, and Resin-Modified Glass Ionomer Cement and Mode of Fracture: An In Vitro Study
}

\author{
Salil Mehra ${ }^{1}$ Ashu K. Gupta ${ }^{1} \quad$ Bhanu Pratap Singh ${ }^{1} \quad$ Mandeep Kaur ${ }^{1} \quad$ Ashwath Kumar $^{1}$ \\ ${ }^{1}$ Department of Conservative Dentistry and Endodontics, \\ Government Dental College, Shimla, Himachal Pradesh, India

\begin{abstract}
Address for correspondence Salil Mehra, Department of Conservative Dentistry and Endodontics, Government Dental College, Shimla 171001, Himachal Pradesh, India (e-mail: salil7salil@gmail.com).
\end{abstract}

Dent J Adv Stud 2020;8:49-54

\begin{abstract}
Introduction The aim of the current study was to evaluate shear bond strength of resin composite bonded to Theracal LC, Biodentine, and resin-modified glass ionomer cement (RMGIC) using universal adhesive and mode of fracture.

Materials and Methods A total of 50 caries-free maxillary and mandibular molars extracted were taken; occlusal cavities were prepared, mounted in acrylic blocks, and divided into five groups based on the liner used. Group 1: Biodentine liner placed into the cavity and bonding agent and resin composite applied after 12 minutes. Group 2: Biodentine liner placed into the cavity and bonding agent and resin composite applied after 14 days. Group 3: RMGIC liner placed into the cavity and bonding agent and resin composite applied immediately. Group 4: RMGIC liner placed into the cavity and bonding agent and resin composite applied after 7 days. Group 5: Theracal LC liner placed into the cavity and bonding agent and resin composite applied immediately. Each sample was bonded to resin composite using universal adhesive. Shear bond strength analysis was performed at a cross-head speed of $0.1 \mathrm{~mm} / \mathrm{min}$.

Keywords

- biodentine

- resin-modified glass ionomer

- theracal LC TM

Statistical Analysis Statistical analysis was performed with one-way analysis of variance and posthoc Bonferroni test using SPSS version 22.0.

Results and Conclusion Biodentine liner when bonded immediately to resin composite showed minimum shear bond strength. RMGIC when bonded to resin composite after 7 days showed maximum shear bond strength. Mode of fracture was predominantly cohesive in groups having Biodentine and Theracal LC as liner.
\end{abstract}

\section{Introduction}

Newer bioactive restorative materials have been generated with a possibility of remineralization. Some restorative materials which are capable of interacting with tooth structure have been the subject of interest recently. Such protective biomaterials ought to possess specific bio-properties like biocompatibility, bio-interactivity and bioactivity to bolster the pulp cell activity and formation of reparative dentin. Bioactive materials are the materials that evoke specific and predictable cell and tissue responses. The ability to form apatite is called "bioactivity." Some materials lead to the formation of a layer underneath them which has high mineral content, and this process is known as biomineralization.

The use of bioactive liners beneath resin composite would clinically be more advantageous than using glass ionomer liners as they are biologically well-tolerated by the pulp tissue and have comparatively higher remineralizing ability. ${ }^{2}$ The concept of bioactivity is linked to bio-integrity. Shear bond strength of the liner to resin composite and tooth 
structure is related to the success of restoration when laminate restorations are placed. Resin-modified glass ionomer cements (RMGIC) are modified glass ionomer cements made to have additional properties of resin composites. It has not been clearly defined how long the acid base reaction of glass ionomer cement continues. The bond strength of RMGIC to resin composite varies, depending on the kind of adhesive used. ${ }^{3}$ Biodentine is recently being used as a dentine replacement material underneath composite restorations. ${ }^{4}$ Tricalcium silicate and zirconia carbonate are major constituents of Biodentine. It releases calcium hydroxide after setting and thus possesses the property to induce mineralization. So, the use of Biodentine in place of glass ionomer cement as a liner or base can prove to be beneficial. Silica is a stronger inducer for dentine matrix remineralization than fluoride ions of RMGIC.

Hashem et $\mathrm{al}^{5}$ suggested that composite restorations over Biodentine can be completed in two appointments. A waiting period of 2 weeks is required, so that physiochemical properties of Biodentine are able to counter the forces created by contraction of resin composite. Longevity of the restoration depends on the quality of bond created between composite and Biodentine.

Theracal (TLC) is a modified mineral trioxide aggregate (MTA) which contains resins; therefore, it is a light curable material and sets immediately. It can also be used as a liner beneath permanent restoration. Theracal has been shown to have good sealing properties.

Both Dycal and ProRoot MTA show lower calcium release as compared with Theracal. ${ }^{6}$ Theracal provides an environment which is highly alkaline. ${ }^{7}$ The release of calcium by Theracal is sufficient to induce the formation of hard tissue. Current literature provides limited information about bonding between resin composite and Theracal. Behavior of calcium silicate materials and products formed by their hydration get influenced by the process of manufacturing the material.

Single bond universal adhesive can be used either as self or selective etch agent. ${ }^{2}$ In the current study, it was proposed to not only evaluate the shear bond strengths of Biodentine, RMGIC, and Theracal when these materials bond to resin composite with universal adhesive but also mode of fracture. Null hypothesis was that shear bond strength of all liners in different groups would be the same.

\section{Materials and Methods}

A total of 50 molars (maxillary and mandibular) were taken. All the teeth were caries free and extracted for non-endodontic reasons. Ultrasonic sealers were used to clean the

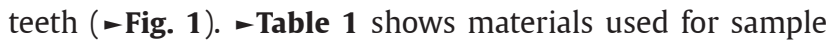
preparation.

With the help of a diamond disc, occlusal surfaces were grinded and made flat. Molds were made $(15 \mathrm{~mm} \times 25 \mathrm{~mm})$ and teeth were mounted in acrylic blocks made of molds (-Fig. 2). Acrylic was filled to the level of occlusal surfaces of teeth. Straight fissure carbide bur was used to make rectangular cavities having depth and length of $2 \mathrm{~mm}$ and $6 \mathrm{~mm}$,

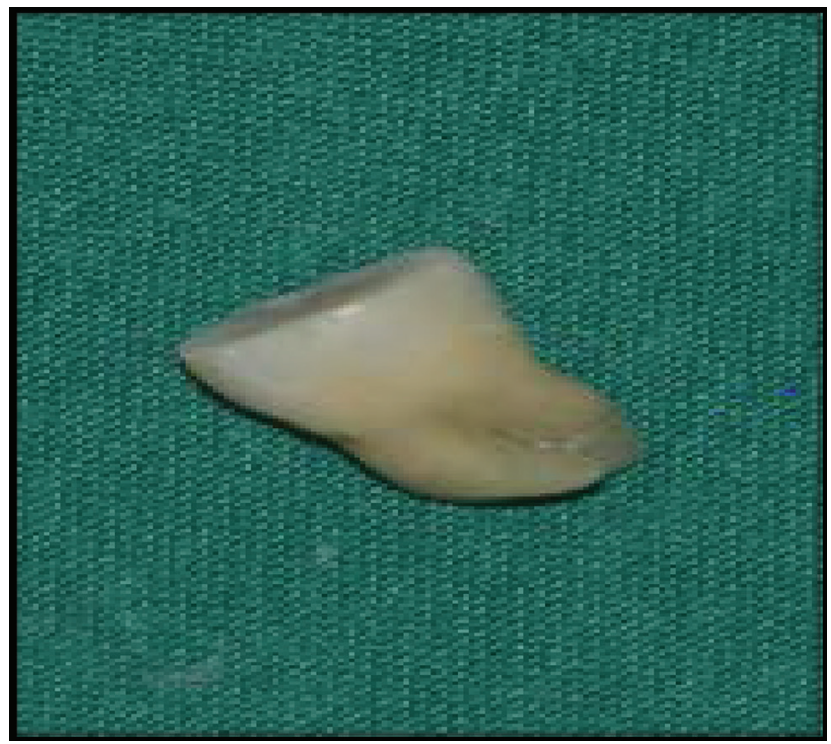

Fig. 1 Molars with flattened occlusal surface.

Table 1 Materials used in study

\begin{tabular}{|l|l|l|}
\hline Material & $\begin{array}{l}\text { Manufacturer } \\
\text { lot no. }\end{array}$ & Mode of application \\
\hline Biodentine & Septodont & $\begin{array}{l}\text { Biodentine was mixed accord- } \\
\text { ing to the manufacturer's } \\
\text { instructions and then placed } \\
\text { in prepared cavities }\end{array}$ \\
\hline $\begin{array}{l}\text { Resin- } \\
\text { modified } \\
\text { glass iono- } \\
\text { mer cement } \\
\text { (RMGIC) }\end{array}$ & G C Gold & $\begin{array}{l}\text { RMGIC was mixed as sug- } \\
\text { gested by manufacturer and } \\
\text { placed in two increments in } \\
\text { prepared cavities and each } \\
\text { increment was light cured for } \\
\text { 20 seconds }\end{array}$ \\
\hline $\begin{array}{l}\text { Theracal LC } \\
\text { TLC was applied directly into } \\
\text { the cavity and then light cured } \\
\text { for 20 seconds. TLC was also } \\
\text { applied in two increments to } \\
\text { attain proper curing of the } \\
\text { whole of the liner placed }\end{array}$ \\
\hline $\begin{array}{l}\text { Resin } \\
\text { composite }\end{array}$ & $\begin{array}{l}\text { Nanocomposite } \\
\text { Coltene }\end{array}$ & $\begin{array}{l}\text { Light polymerize for } \\
\text { 40 seconds }\end{array}$ \\
\hline $\begin{array}{l}\text { Universal } \\
\text { dental } \\
\text { adhesive }\end{array}$ & $\begin{array}{l}\text { One coat bond } \\
\text { Coltene }\end{array}$ & $\begin{array}{l}\text { Scrub in for 20 seconds, and } \\
\text { air dry until the adhesive } \\
\text { does not move. Light cure for } \\
\text { 20 seconds }\end{array}$ \\
\hline
\end{tabular}

respectively ( $\bullet$ Fig. 3 ). All teeth were divided into five groups, and the division was carried out randomly (-Table 2 ).

Adhesive was applied by rubbing with applicator tips. It was light cured after air drying for 5 seconds, and then resin composite was placed over the liner in the polytetrafluoroethylene tube (PTFA) $(2 \mathrm{~mm} \times 2 \mathrm{~mm}$, i.e., diameter and height). Thereafter, photoactivation was done. A sharp knife was used to cut the PTFA tube. Thereafter, samples were kept in water for 24 hours at $37^{\circ} \mathrm{C}$.

\section{Shear Bond Strength Assessment}

The samples were prepared. Each sample was placed for bond strength assessment in the universal testing machine 


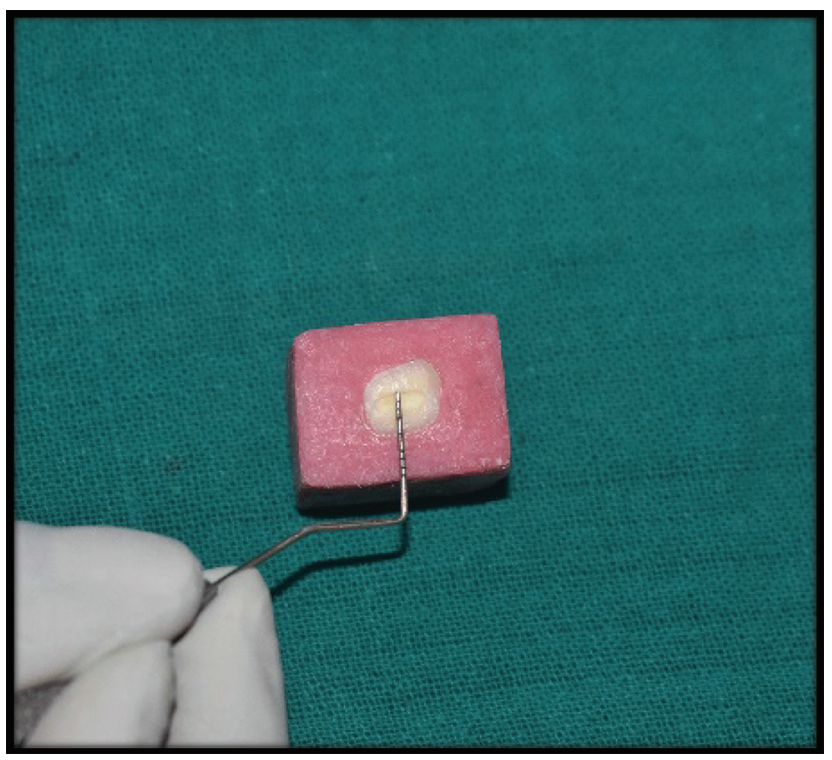

Fig. 2 Prepared occlusal cavity.

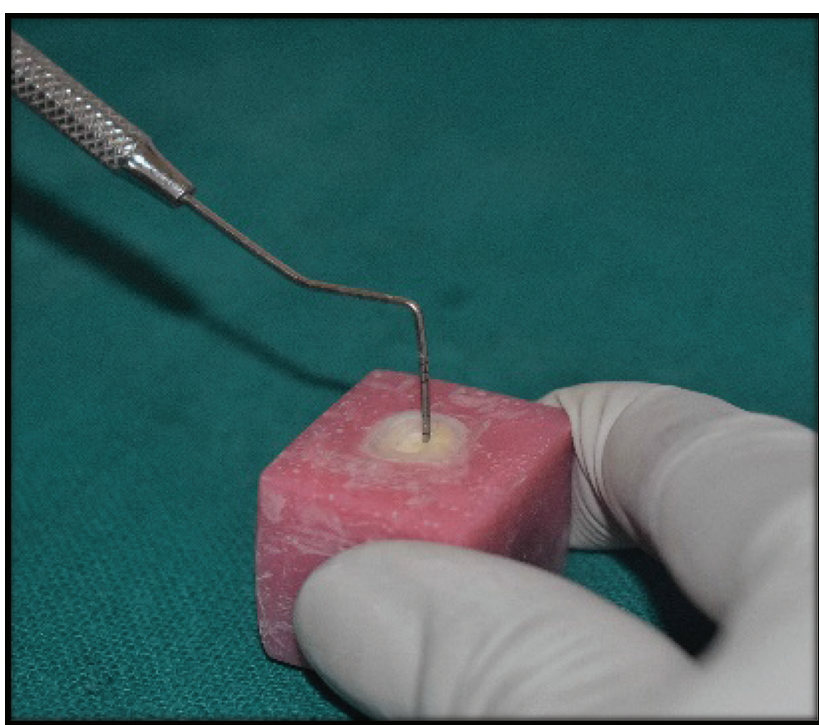

Fig. 3 Final specimen prepared for testing under universal testing machine.

Table 2 Grouping of samples

\begin{tabular}{|l|l|l|}
\hline Group & Liner used & $\begin{array}{l}\text { Time interval } \\
\text { between liner and } \\
\text { resin composite } \\
\text { placement }\end{array}$ \\
\hline 1 & Biodentine & 12 minutes \\
\hline 2 & Biodentine & 14 days \\
\hline 3 & RMGIC & Immediately placed \\
\hline 4 & RMGIC & 7 days \\
\hline 5 & Theracal LC & Immediately placed \\
\hline
\end{tabular}

(HEICO) ( Fig. 4). A knife edge chisel was gently held flush against liner and resin composite interface. Cross-head speed of loading was $0.1 \mathrm{~mm} / \mathrm{min}$. The force at which fracture

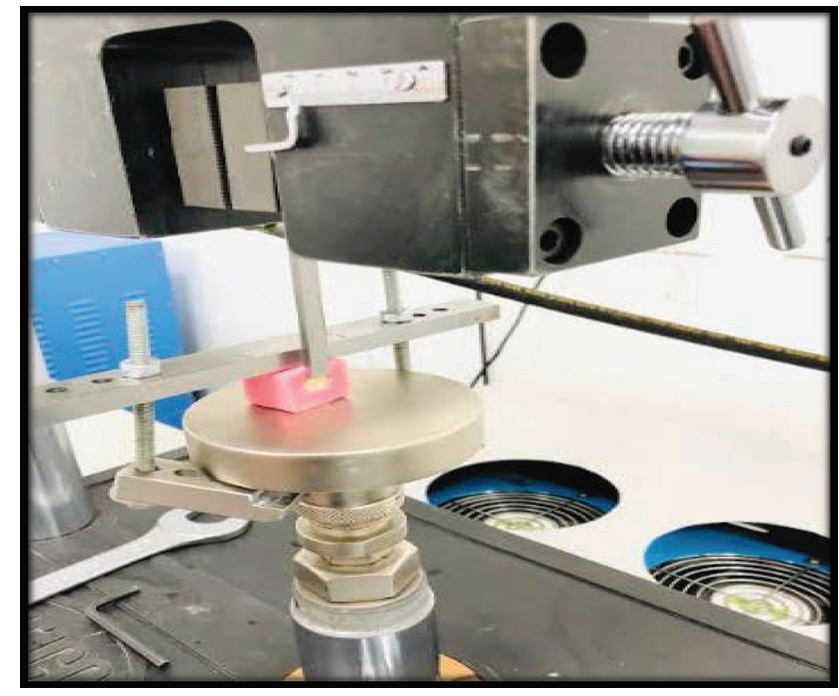

Fig. 4 Lading of sample using universal testing machine.

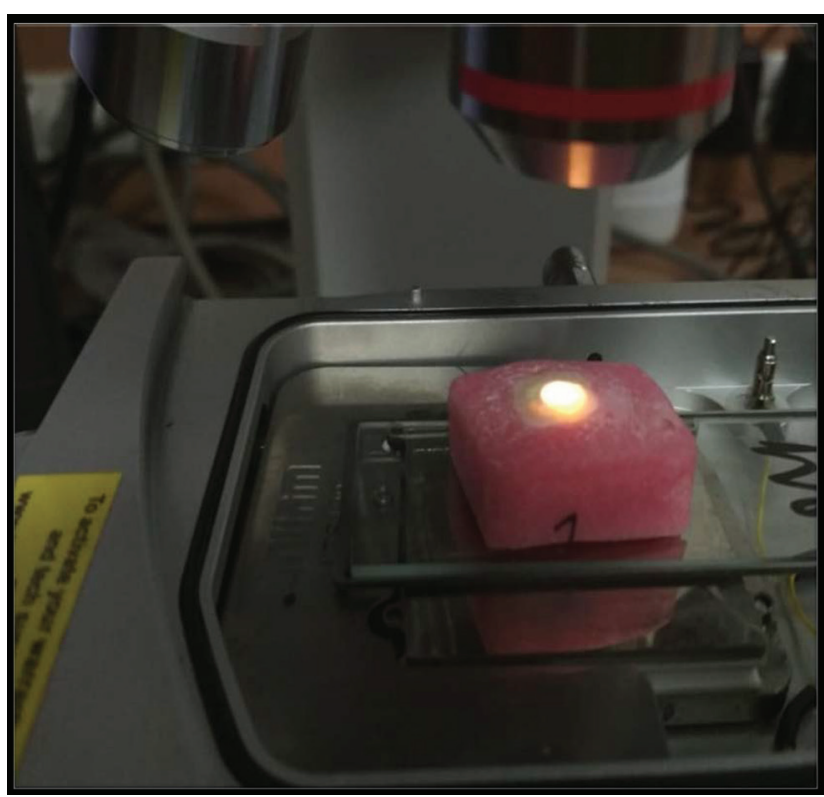

Fig. 5 Specimen under optical microscope.

occurred was registered. The values were translated to Mpa. An abrupt change in force versus time graph was taken as failure load.

\section{Assessment of Mode of Fracture}

Magnification of $\times 100$ ( - Fig. 5) under optical microscope (NIKON) was used to check the mode of fracture for each sample. Cohesive, adhesive and mixed modes of fracture were observed.

\section{Statistical Assessment}

Microsoft excel spreadsheet and SPSS version 22.0 was used for processing the data. Descriptive statistics were used to summarize the recorded values. ANOVA test and posthoc Bonferroni test were used to compare intergroup and intragroup mean values. Statistically significant $p$ value was $<0.05$. 


\section{Results}

- Table 3 shows mean values. Biodentine liner showed minimum values. RMGIC group with resin composite placed after 7 days showed maximum shear bond strength. Both Biodentine and RMGIC showed increase in shear bond strength when bonding to resin composite was delayed (-Fig . 6).

Mode of fracture was predominantly cohesive in groups having Biodentine (immediately bonded to resin composite) and Theracal as a liner. The second group of Biodentine as liner where application of resin composite was delayed had most adhesive fractures. Groups with RMGIC as liner showed predominantly mixed mode of fracture. Mode of fracture of different groups is shown in - Fig. 7 .

\section{Discussion}

Pulp capping procedures take advantage of the ability of liner materials to induce the formation of reparative dentine. These materials stimulate pulp organ either by being directly placed over pulp tissue, as in direct pulp capping procedures, or when placed in close proximity to pulp over thin remaining dentin, as in indirect capping procedures. This deposition of tertiary dentine increases the distance between the site of injury and the pulp, and reduces dentine permeability by the formation of sclerotic dentine.
A pulp capping agent should also possess certain biochemical and physical properties like adhesion to restorative materials, radio-opacity, bacterial seal, and being bacteriostatic or bactericidal. It should also have sufficient shear bond strength to the overlying restoration.

Different materials have been tried as liner over the years. Calcium hydroxide is the most widely used material; however, it has certain disadvantages. They include tunnel defects, dissolution with time, and unsatisfactory adherence to dentin.

Shear bond strength of a material shows its strength against the forces which produce a failure parallel to direction of force.

RMGIC has also been used as a liner or base in sandwich technique with resin composite. The advantage of RMGIC is its property to bond to the tooth and its coefficient of thermal expansion, which is similar to coefficient of thermal expansion of dentin.

Recently, tricalcium-based materials have been introduced to be used as cavity liners and pulp capping materials. Hydration reaction of MTA produces calcium hydroxide and calcium silicate hydrate. MTA has long setting time. Second generation calcium silicate materials are newer materials. Biodentine is one such material. Mechanical and handling properties of Biodentine are better and setting time is shorter when compared with MTA. The initial setting time

Table 3 Showing mean bond strength

\begin{tabular}{|l|l|l|l|l|}
\hline Group & N & Mean & SD & Standard error mean \\
\hline 1 & 10 & 4.7106 & .64990 & .20552 \\
\hline 2 & 10 & 9.4130 & .59907 & .18944 \\
\hline 3 & 10 & 18.6890 & .59993 & .18972 \\
\hline 4 & 10 & 26.5190 & 1.05757 & .33443 \\
\hline 5 & 10 & 17.5110 & .84876 & .26840 \\
\hline
\end{tabular}

Abbreviation: SD, standard deviation.

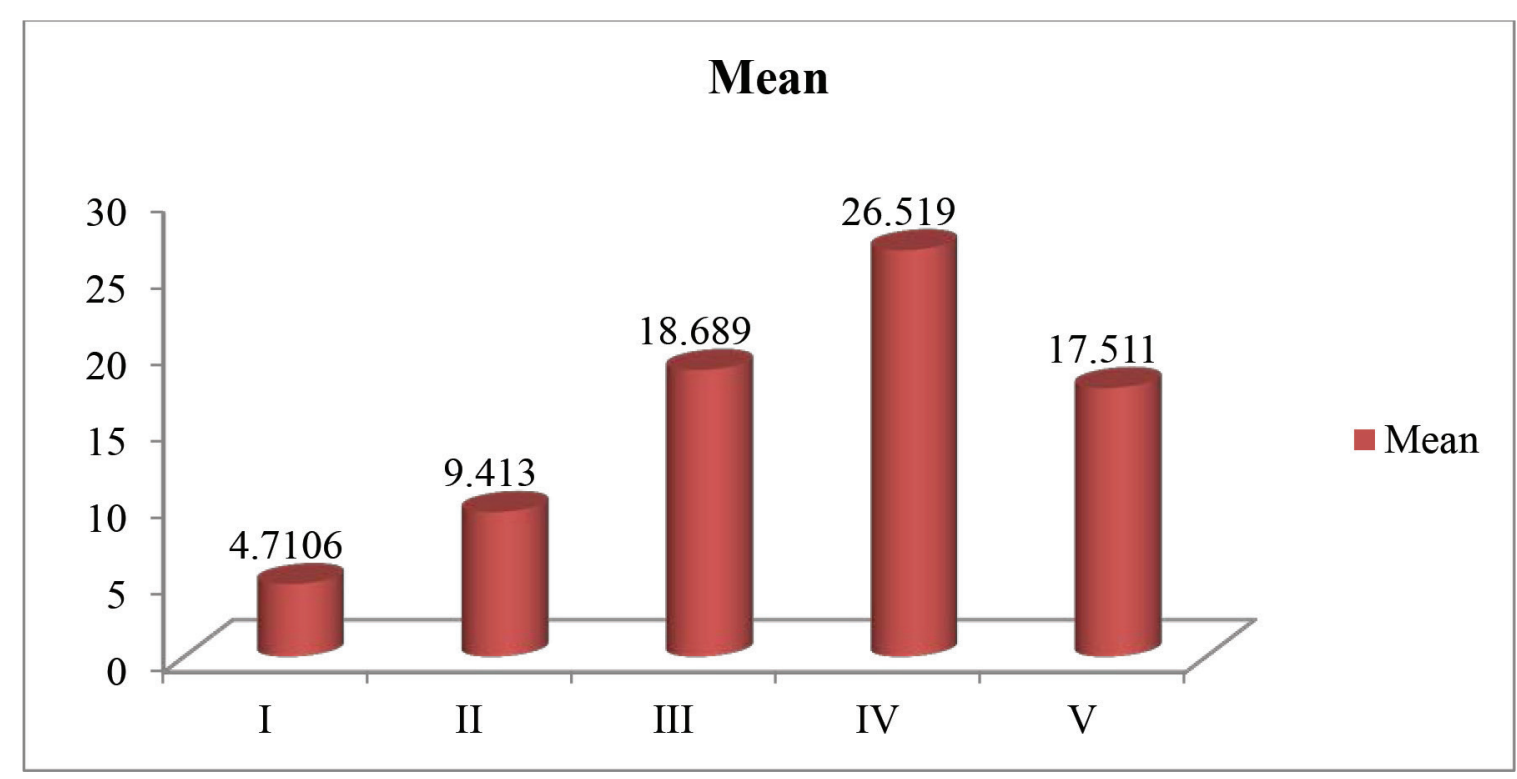

Fig. 6 Mean shear bond strength in studied groups. 


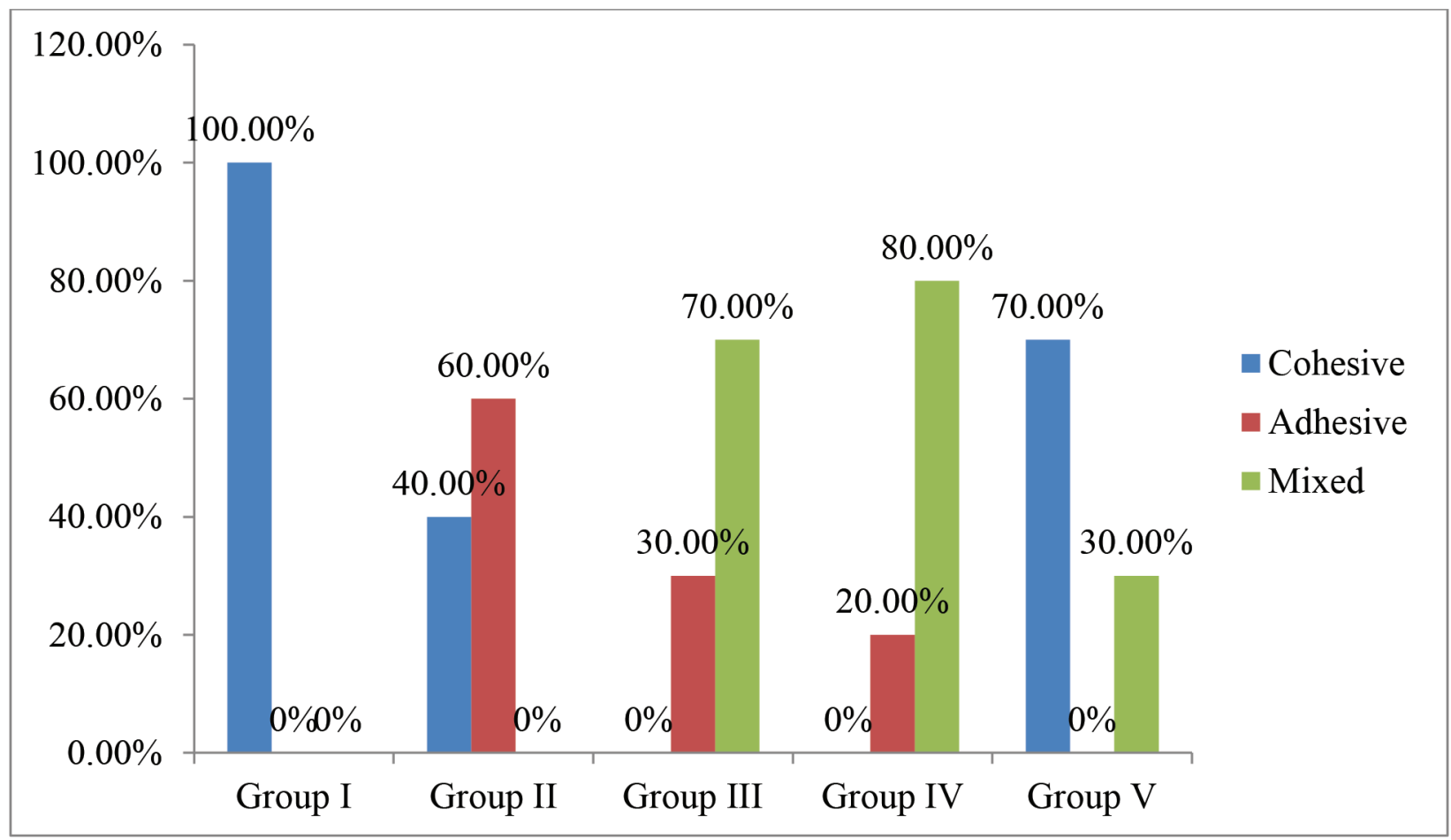

Fig. 7 Frequency distribution of mode of fracture among studied groups.

of Biodentine is 9 to 12 minutes, while the final reaction is believed to occur for as long as 14 days.

Theracal can further simplify the handling and setting characteristics of calcium silicate liners, as it can be light cured and can be placed into prepared tooth directly with syringe. ${ }^{8}$ A chemical adhesion builds between Theracal and Biodentine.

Restorative material of choice in most cases is resin composite because of its better aesthetics, ability to bond with enamel, need for minimal removal of tooth structure, and acceptable longevity; therefore, resin composite was selected in current study as restorative material.

Biodentine and Theracal being the newer and modified materials have advantages over traditionally used MTA. RMGIC is standard material used in sandwich restorations with resin composite. Therefore, these three materials were selected as liner.

Shear bond strength of Biodentine was measured at 12 minutes and 2 weeks interval because studies have shown variation in initial and final setting time of Biodentine. Although RMGIC sets immediately after photo activation and attains sufficient bulk strength, delayed reaction continues to occur. So, shear bond strength of RMGIC was evaluated to resin composite in two similar scenarios, that is, when permanent restoration was placed immediately or after interval of 7 days.

Currently, limited studies have evaluated shear bond strength of Theracal. Moreover, not much has been discussed about delayed setting of this material. Therefore, shear bond strength of Theracal was evaluated after immediate placement of resin composite over liner.

Self-etching adhesive has shown lower bond strength than total-etch adhesive when used for bonding composite resin and dentine. ${ }^{9}$ A study by Takamizawa et al reported similar findings and better shear bond strength with total-etch adhesive. $^{10}$

Shear bond strength of flowable composite to TLC has been shown to be greater than that of Biodentine and MTA according to Gaddalay et $\mathrm{al}^{11}$ Studies have also shown shear bond strength of Biodentine to hike over a 24-hour period. ${ }^{12}$ Two visits procedure has been preferred according to some authors. ${ }^{13}$

RMGIC has shown statistically significant higher leakage values as compared with Theracal and Biodentine when used as a liner beneath closed sandwich restorations.

As Darsan et al have said that Theracal has comparable shear bond strength to RMGIC to work fine beneath resin composite restorations, it can easily be considered as an alternative to RMGIC. ${ }^{14}$

The null hypothesis that there would be no difference in shear bond strength of different liners was rejected.

Mode of fracture in first group Biodentine bonded after 12 minutes were all cohesive. They can be attributed to low early bulk strength of the material. As the material attained more bulk strength over the time in the second group, adhesive mode of fracture was seen. Theracal group had most of cohesive and few mixed modes of fracture. Cohesive failure in Theracal could have been due to its low bulk strength. This might show cohesive strength of material rather than true interfacial bond strength. Some of the adhesive might spread over the area, which is larger than that of the surface area of resin composite, and therefore cause alteration in stress distribution. Because of this excess adhesive, the fractured area actually became more, as compared with the interfacial area under study. 
Both the groups of RMGIC, group 3 and group 4 (bonded immediately and after 7 days), showed few adhesive failures, but predominantly mixed mode of failure was seen in RMGIC. The study of Deepa et al showed similar results where Biodentine and Theracal showed cohesive mode of fracture and RMGIC showed mainly mixed mode of fracture. ${ }^{2}$

Within the limitations of this study, it can be interpreted that RMGIC, when used as a liner bonded to resin composites after 7 days, showed maximum shear bond strength and Biodentine when bonded after a timeframe of 12 minutes to resin composite showed minimum shear bond strength.

\section{Conclusion}

Within the limitations of the present in vitro study, it is concluded that Biodentine when bonded to resin composite immediately has low shear bond strength, which increases when bonding is delayed for 2 weeks. Theracal has lower shear bond strength than RMGIC but significantly higher shear bond strength than Biodentine.

\section{Conflict of Interest}

None declared.

\section{References}

1 Reyes-Carmona JF, Felippe MS, Felippe WT. Biomineralization ability and interaction of mineral trioxide aggregate and white portland cement with dentin in a phosphate-containing fluid. J Endod 2009;35(5):731-736

2 Deepa VL, Dhamaraju B, Bollu IP, Balaji TS. Shear bond strength evaluation of resin composite bonded to three different liners: TheraCal LC, Biodentine, and resin-modified glass ionomer cement using universal adhesive: An in vitro study. J Conserv Dent 2016;19(2):166-170

3 Arora V, Kundabala M, Parolia A, Thomas MS, Pai V. Comparison of the shear bond strength of RMGIC to a resin composite using different adhesive systems: An in vitro study. J Conserv Dent 2010;13(2):80-83

4 Camilleri J. Investigation of Biodentine as dentine replacement material. J Dent 2013;41(7):600-610

5 Hashem DF, Foxton R, Manoharan A, Watson TF, Banerjee A. The physical characteristics of resin composite-calcium silicate interface as part of a layered/laminate adhesive restoration. Dent Mater 2014;30(3):343-349

6 Gandolfi MG, Siboni F, Prati C. Chemical-physical properties of TheraCal, a novel light-curable MTA-like material for pulp capping. Int Endod J 2012;45(6):571-579

7 Cantekin K. Bond strength of different restorative materials to light-curable mineral trioxide aggregate. J Clin Pediatr Dent 2015;39(2):143-148

8 CamilleriJ.Hydration characteristics of Biodentine and Theracal used as pulp capping materials. Dent Mater 2014;30(7): 709-715

9 Hegde MN, Bhandary S. An evaluation and comparison of shear bond strength of composite resin to dentin, using newer dentin bonding agents. J Conserv Dent 2008;11(2):71-75

10 Takamizawa T, Barkmeier WW, Tsujimoto A, et al. Influence of pre-etching times on fatigue strength of self-etch adhesives to enamel. J Adhes Dent 2016;18(6):501-511

11 Gaddalay S, Nagargoje G, Kale A, Hariramani S, Agrawal M, Gelda A. A comparative evaluation of shear bond strength of flowable composite with Theracal LC, Biodentine and Mineral Trioxide aggregate: an in-vitro study. Int J Current Advanced Research 2018;7(3C):10639-10642

12 Odabaş ME, Bani M, Tirali RE. Shear bond strengths of different adhesive systems to biodentine. ScientificWorldJournal 2013;2013:626103

13 Tsujimoto M, Tsujimoto Y, Ookubo A, et al. Timing for composite resin placement on mineral trioxide aggregate. J Endod 2013;39(9):1167-1170

14 Darsan J, Pai VS, Gowda VB, Krishnakumar GR, Nadig RR. Evaluation of gingival microleakage in deep class II closed sandwich composite restoration: an in vitro study. J Clin Diagn Res 2018;12(1):ZC01-ZC05 